\title{
DESIGN OF GPS MICROSTRIP SQUARE PATCH ANTENNA
}

\section{* Suheir H. Fadhil ${ }^{1}$}

\author{
Prof. Dr. Raad H. Thaher ${ }^{2}$
}

1) Department of Electrical Engineering, Mustansiriyah University, Baghdad, Iraq.

2) Department of Electrical Engineering, Mustansiriyah University, Baghdad, Iraq.

\begin{abstract}
In this paper, a new design of microstrip antenna with a square patch for Global Positioning System (GPS) operating at a frequency of $1.227 \mathrm{GHz}$ (L2-band) is presented. The design is printed on the FR4 substrate has a relative permittivity equals to 4.3 and a thickness of 1.6 $\mathrm{mm}$ and loss tangent equals 0.0025 . The antenna having return loss $\mathrm{S} 11=-69.782 \mathrm{~dB}$, gain $=4.9952 \mathrm{dBi}$, and voltage standing wave ratio VSWR $=1.0006$ at $f=1.265$ $\mathrm{GHz}$ for all previously results. The antenna is designed using CST microwave studio version 2019.
\end{abstract}

Keywords: GPS, return loss, VSWR, Microstrip antenna.

\section{Introduction}

The Global Positioning System (GPS) is a satellite-based navigation technology developed by the United States Department of Defense (DoD) at the turn of the 1970s. GPS was originally developed as a military system to meet the military needs of the U.S. It was, however, made open later to civilians, and is now a system with a dual-use that both military and civilian users can access. [1]. The system offers users with accurate, ongoing, global, information about three-dimensional position and velocity. [2].
The advancement of lightweight, antennas contributes significantly to the rapid proliferation of civilian and military telecommunications applications, for example, GPS [3]. With the development of navigational technologies, mapping, and satellite communication, there is a persistent need for antenna coverage to reach quickly the weak satellite signals. [4]. The majority of GPS receiver antennas necessitate a circular polarization, thus, microstrip patch antennas (MPAs) are best suited for this purpose. $[3,5]$.

Too many of the advantages of the MPA like low profile, lightweight, compact size, uncostly, easy to mass-produce utilizing printed device technologies. the sense that the antenna is suited for flat and non-planer surfaces, and is suited for Microwave Integrated Circuit Designs (MICs). [4, 6-12]. Even so, there are some of the weaknesses such as reduced bandwidth, poor polarization, and low efficiency [6,7].

The theory and design of antennas have been among the most important subjects over the last

*Corresponding author: Suheir.hazem@gmail.com 
few years. [6,12]. The Microstrip Antenna (MSA) definition goes back to the start of the 1950s. When Deschamps proposed it in the U.S.A and got a patent by Guttan and Baissinot in France. The development of the MSA antenna over the next 15 years has shown little interest. Due to the lack of microwave substrates and due considerable attention to waveguide plates. the interest in the microstrip antenna began in 1973. $[6,7,12-15]$.

Several types of MSAs exist, and they can be designed to have various shapes and sizes due to their physical characteristics. MPA is the most common and simple antennas. A rectangular form MPA consists of very thin of patch thickness $(\mathrm{t})$ is usually $(\mathrm{t}<<\lambda \mathrm{o})$. The patch width is in the range of $0.3333 \lambda_{\mathrm{o}}<\mathrm{W}<0.5 \lambda_{0}$. The height of the substrate is usually $0.003 \lambda_{\mathrm{o}} \leq \mathrm{h} \leq$ $0.05 \lambda \mathrm{o}$. The dielectric constant of the substrate is typically $2.2 \leq \varepsilon r \leq 16$. The patch can be in a variety of shapes like an elliptical, triangular, circular ring, and square or other various forms $[16,17]$.

Some L2-Band GPS researchers published in $[18,19]$. A new configuration of the GPS square patch antenna with a coaxial feeding method and operating at $1.265 \mathrm{GHz}$ (L2-Band) frequency is suggested in this study. The parameters used to design the MPA can be stated as follows [7].

$$
\begin{aligned}
& \mathrm{W}=\frac{c}{2 f_{r}} \sqrt{\frac{2}{\varepsilon_{r}+1}} \\
& \varepsilon_{e f f}=\frac{\varepsilon_{r}+1}{2}+\frac{\varepsilon_{r}-1}{2}\left(1+12 \frac{h}{w}\right)^{-1 / 2} \\
& \frac{\Delta L}{h}=0.412\left(\frac{\varepsilon_{e f f}+0.3}{\varepsilon_{e f f}-0.258}\right)\left(\frac{\frac{w}{h}+0.264}{\frac{w}{h}+0.8}\right) \\
& L_{e f f}=\frac{c}{2 f_{r}} \times \frac{1}{\sqrt{\varepsilon_{e f f}}}
\end{aligned}
$$

$L=L_{e f f}-2 \Delta l$

Where:

$\mathrm{W}=$ the patch width.

$\varepsilon_{r}=$ the dielectric constant of substrate.

$\varepsilon_{e f f}=$ the effective dielectric constant.

$f_{r}=$ the operating resonance frequency.

$\mathrm{h}=$ the height substrate.

$L_{e f f}=$ the effect length of the patch.

$\mathrm{L}=$ the length of the patch.

\section{Antenna design}

The square patch of the model antenna represents the radiating part that is made from a conducting material (copper), and it is etched on the FR4 substrate (Flame Resistant 4) which has a thickness of $1.6 \mathrm{~mm}$, relative permittivity $\varepsilon \mathrm{r}=$ 4.3 , and loss tangent $(\tan \delta=0.025)$. From the bottom side of the substrate, there is another conducting material called the ground layer. Many slots are added to both patch and ground layer to enhance the performance of the designed antenna where the value of return loss became less than $-10 \mathrm{~dB}$ as shown in Fig. 1. The type of the feeding technique used is a coaxial feeding, which is located on the diagonal axis in the point of $(10 \mathrm{~mm}, 10 \mathrm{~mm})$ in the $x-y$ plane. The parameters of the designed antenna are illustrating in table 1. 


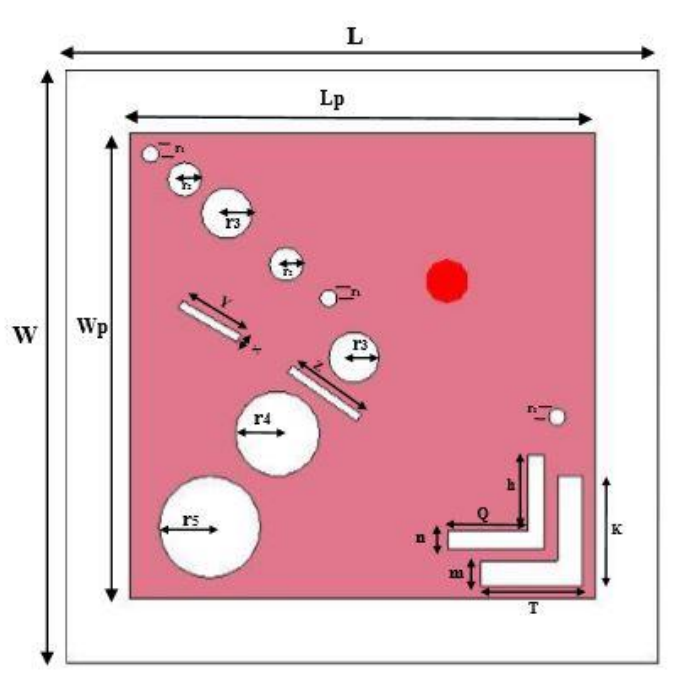

(a)

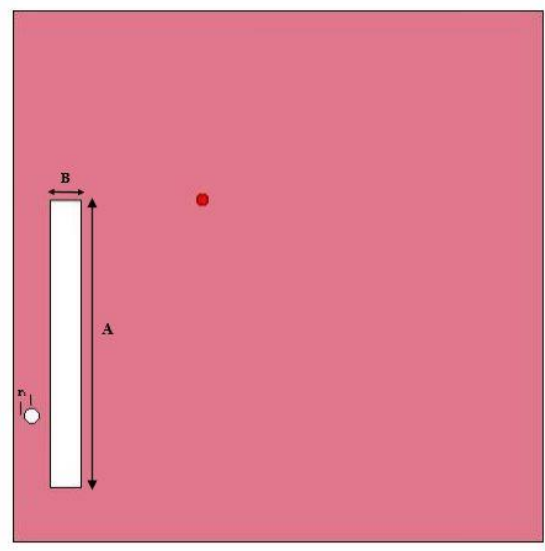

(b)

Fig.1. construction of the modeled antenna (a) top view (b) bottom view.

Table 1. The list of the designed Antenna Parameters.

\begin{tabular}{cc}
\hline Parameter & Value $(\mathrm{mm})$ \\
L & 70 \\
Lp & 55 \\
X & 1 \\
Y & 8 \\
Z & 10 \\
S & 9.5 \\
h & 6
\end{tabular}

\begin{tabular}{ll}
\hline $\mathrm{n}$ & 2 \\
$\mathrm{~m}$ & 3 \\
$\mathrm{~K}$ & 13 \\
$\mathrm{~T}$ & 9 \\
$\mathrm{~A}$ & 38 \\
$\mathrm{~B}$ & 4 \\
$\mathrm{r} 1$ & 1 \\
$\mathrm{r} 2$ & 2 \\
$\mathrm{r} 3$ & 3 \\
$\mathrm{r} 4$ & 5 \\
$\mathrm{r} 5$ & 6 \\
\hline
\end{tabular}

Where:

$\mathrm{L}=$ length of the substrate $=\mathrm{W}$

$\mathrm{Lp}=$ length of the patch plane $=\mathrm{Wp}$

$\mathrm{r} 1, \mathrm{r} 2, \mathrm{r} 3, \mathrm{r} 4, \mathrm{r} 5=$ the radiuses of the circular slots.

$\mathrm{X}, \mathrm{Y}, \mathrm{Z}, \mathrm{S}, \mathrm{h}, \mathrm{n}, \mathrm{m}, \mathrm{K}, \mathrm{T}, \mathrm{A}, \mathrm{B}=$ the dimensions of the other slots.

Some parametric study such as changing in Lp, Wp, and feeding point position $\mathrm{P}$ have been carried out to improve the performance of the antenna as follows:

\subsection{Effect of Changing the patch length $L p$}

Varying the length of the patch can be noticed from Fig. 2 where there is a significantly changing in the reflection coefficient where the best value can get it when Lp equals $55 \mathrm{~mm}$ with obtained the value of $\mathrm{S} 11=-69.782 \mathrm{~dB}$ at the resonant frequency $\mathrm{f}=1.265$ $\mathrm{GHz}$. 


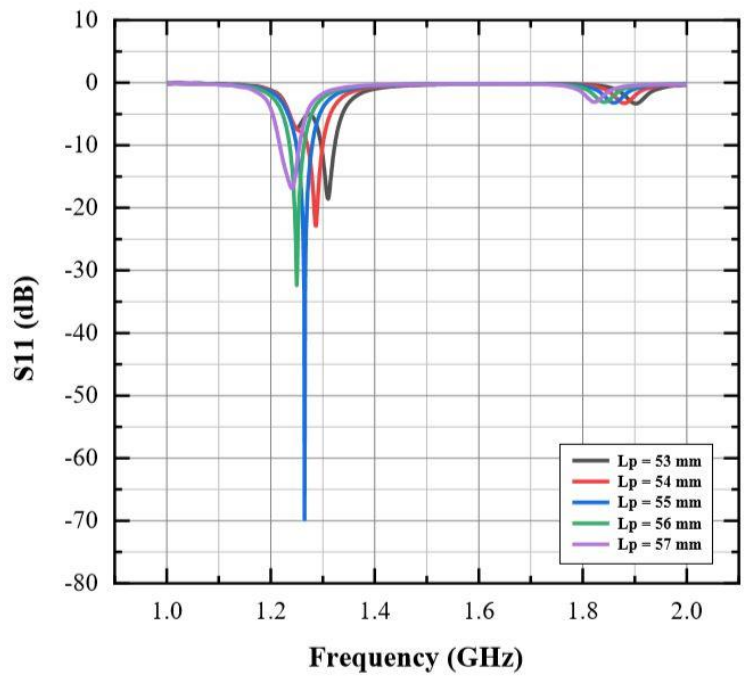

Fig.2. Effect of changing the patch length Lp.

\subsection{Effect of Changing the patch Width Wp}

As shown in Fig. 3, the best value for the reflection coefficient is that when the width of the patch is equal to $55 \mathrm{~mm}$ where the value of $\mathrm{S} 11=$ $-69.782 \mathrm{~dB}$ at the resonant frequency $\mathrm{f}=1.265$ $\mathrm{GHz}$.

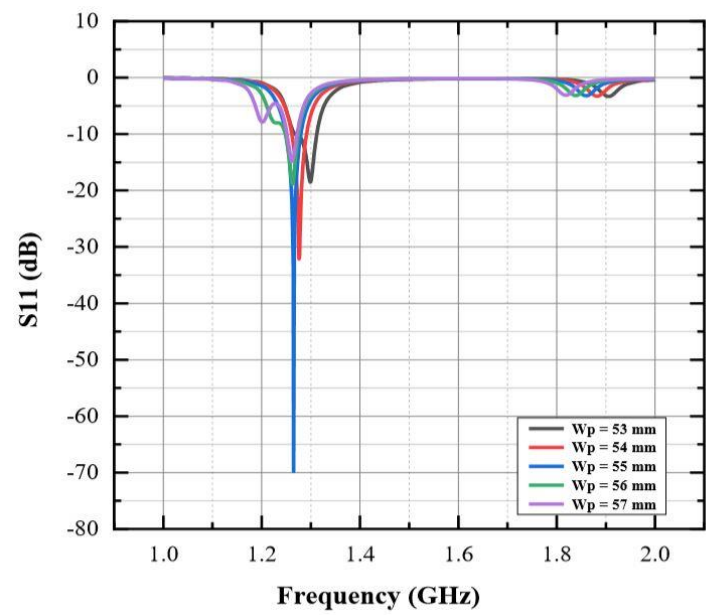

Fig.3. Effect of changing the patch width Wp.

\subsection{Effect of Changing the feeding point position $P$.}

Also, the position of feeding point has been changed as shown in Fig. 4. It is clear that when the point of feeding is located at $(10 \mathrm{~mm}, 10 \mathrm{~mm})$ in the $x-y$ plane, the best value of return loss is equal to $-69.782 \mathrm{~dB}$ at the frequency of 1.265 $\mathrm{GHz}$.

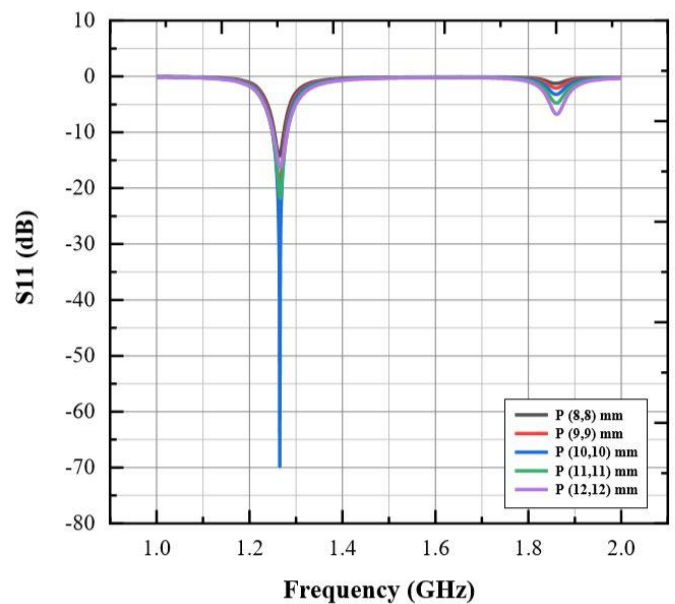

Fig.4 . Effect of changing the position of feeding point $P$

Fig. 5. shows the reflection coefficient of the proposed antenna versus frequency where it is value equals to $-69.782 \mathrm{~dB}$ at the resonance frequency $\mathrm{f}=1.265 \mathrm{GHz}$.

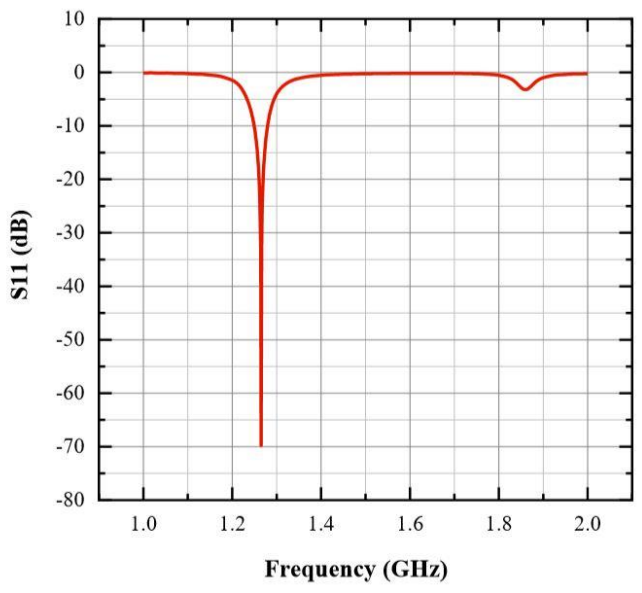

Fig.5. The return loss of the designed antenna

Also, the value of voltage standing wave ratio (VSWR) has been measured as shown in Fig. 6 . Where its value equals to 1.0006 at the frequency $\mathrm{f}=1.265 \mathrm{GHz}$ which is an accepted value where VSWR must be less than 2. The VSWR represents a measure of impedance matching and can be defined as follows:

$$
\mathrm{VSWR}=\frac{\mathrm{Vmax}}{\mathrm{Vmin}}=\frac{1+\gamma}{1-\gamma}
$$

Where $\gamma$ represent the reflection coefficient

$\gamma=\frac{\mathrm{z}_{\mathrm{R}}-\mathrm{Z}_{\mathrm{O}}}{\mathrm{z}_{\mathrm{R}}+\mathrm{z}_{\mathrm{O}}}$

And also

$\mathrm{S} 11=10 \log \gamma$ 


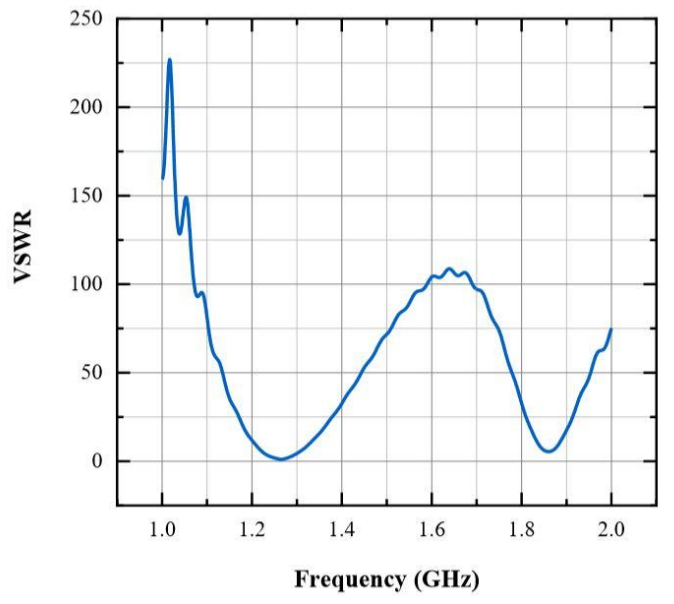

Fig.6. VSWR of the designed antenna.

The antenna has a good gain as illustrated in Fig. 7. Where it equals to $4.9952 \mathrm{~dB}$ at the resonant frequency $\mathrm{f}=1.265 \mathrm{GHz}$.

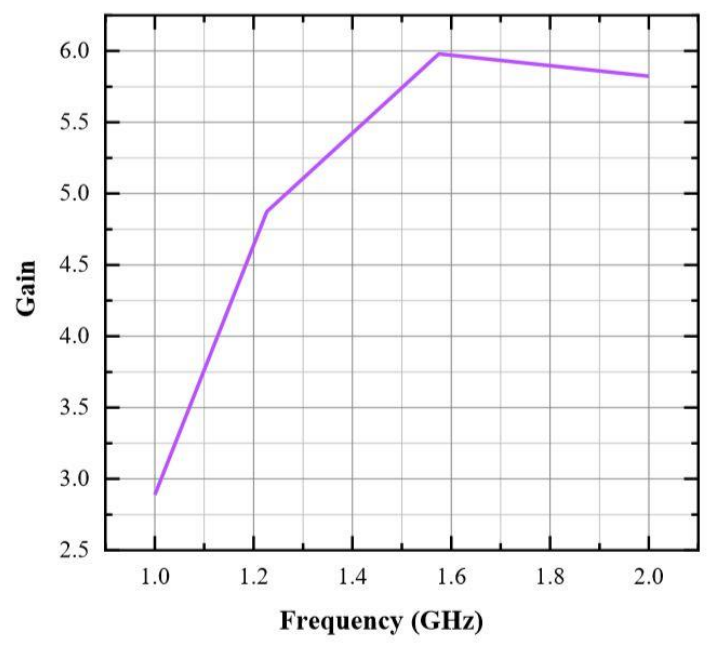

Fig.7. The designed antenna gain

Fig. (8-a) shows the simulation result of the real value of the input impedance where it is equal to $49.968 \Omega$ at the resonant frequency $\mathrm{f}=$ $1.265 \mathrm{GHz}$, while the Fig. (8-b) shows the simulation result of the imaginary value of the input impedance for the designed antenna which equals to -9.2508 e- $05 \Omega$ at the same frequency $\mathrm{f}=1.265 \mathrm{GHz}$.

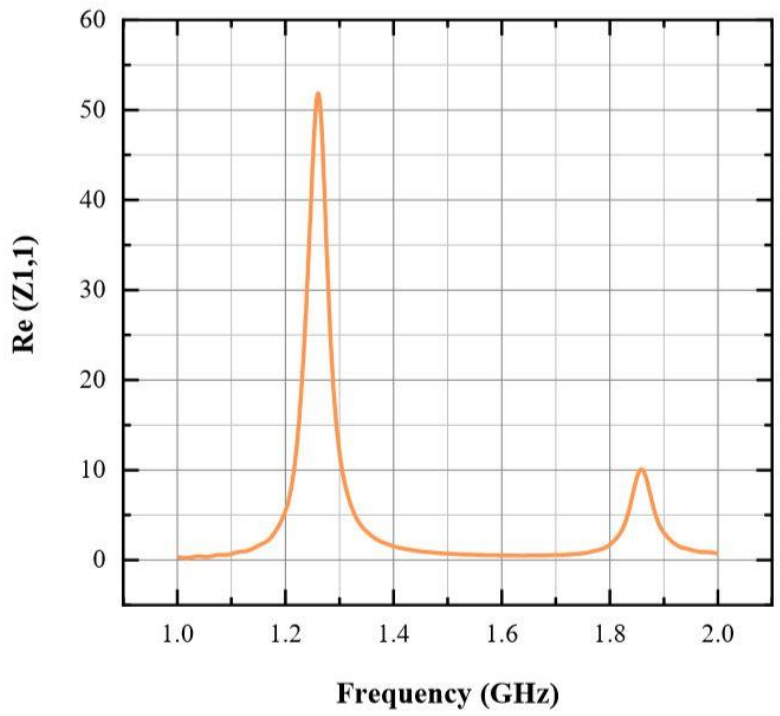

(a)

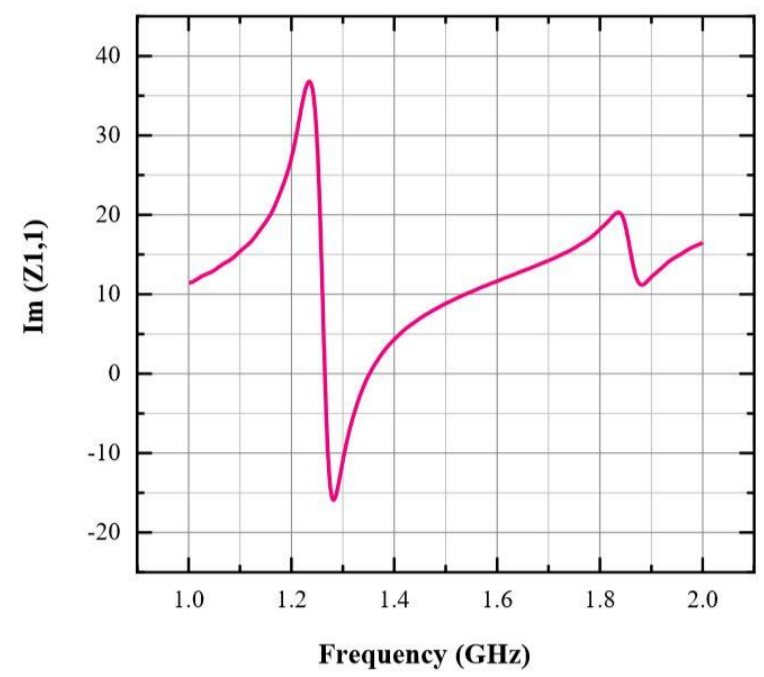

(b)

Fig.8. The simulation results of the input impedance for the designed antenna (a) real part (b) imaginary part.

In Fig. (9-a) the 2-D of the E-field for the designed antenna is illustrated, where the magnitude of the main lob is $5.82 \mathrm{~V} / \mathrm{m}$ in the direction $1.0 \mathrm{deg}$. Where the angular width $(3 \mathrm{~dB})$ is $102.5 \mathrm{deg}$. The $\mathrm{H}$-field of the designed antenna is illustrated in Fig. (9-b) where the main lobe magnitude is equaled to $-45.7 \mathrm{~A} / \mathrm{m}$ in the direction $1.0 \mathrm{deg}$. and the angular width $(3 \mathrm{~dB})$ is $102.5 \mathrm{deg}$. 


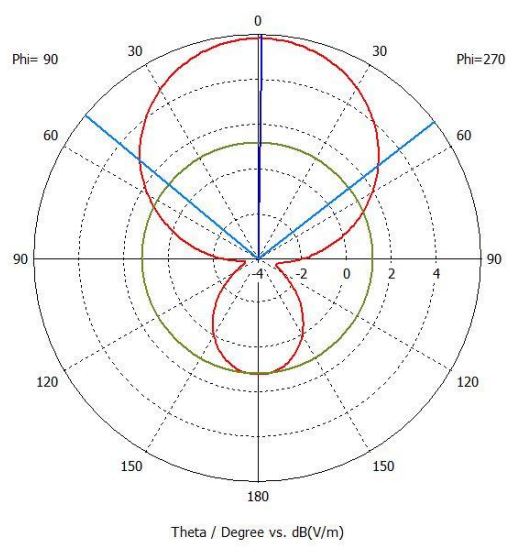

(a)

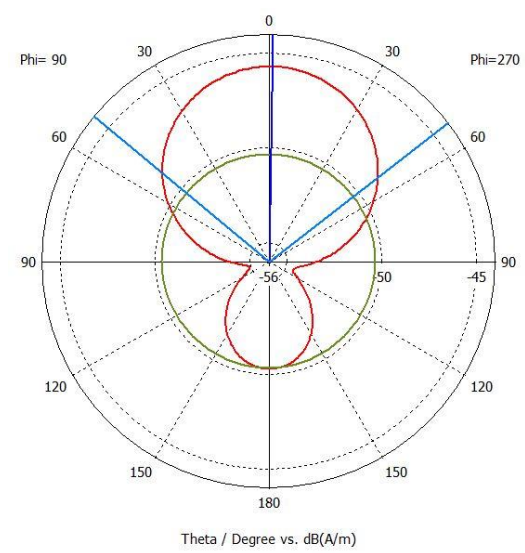

(b)

Fig.9. The radiation pattern of the designed antenna (a) E-field (b) H-field.

The antenna has a maximum current equals to $102.907 \mathrm{~A} / \mathrm{m}$. The most current is distributed at the center of the radiating patch and it drops near the antenna edges as shown in Fig. 10.

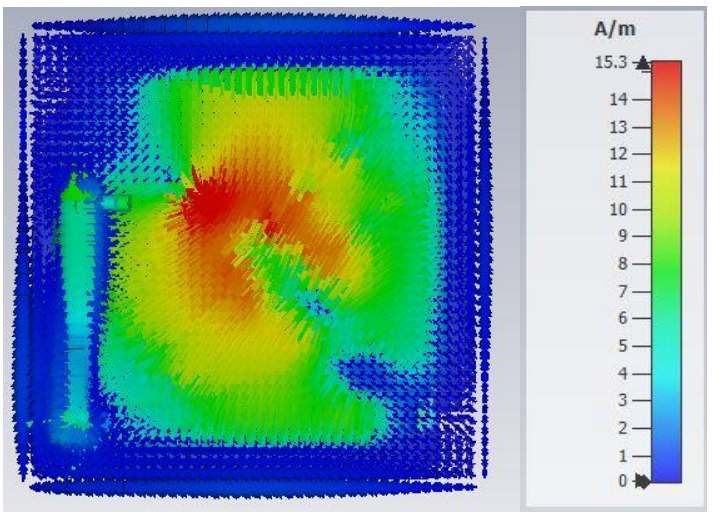

Fig.10 . Distribution of the designed antenna current.

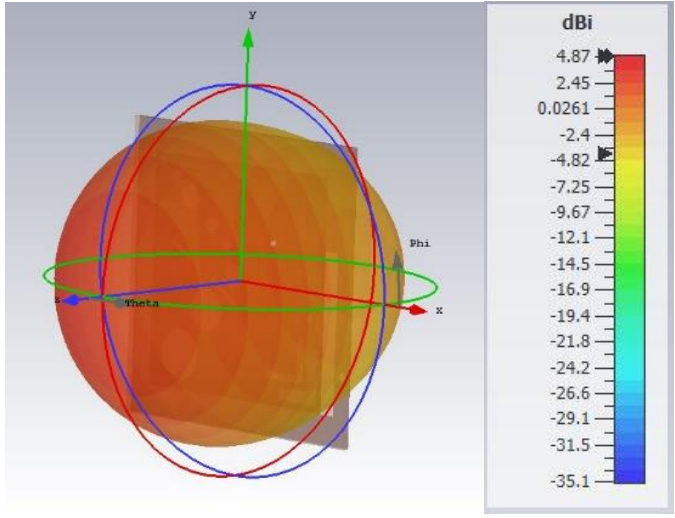

Fig.11. 3-D far-field of the designed antenna.

Table 2. A comparison with other published work.

\begin{tabular}{|c|c|c|c|c|}
\hline Reference & $\begin{array}{l}\text { Antenna } \\
\text { Size } \\
(\mathrm{mm} 2)\end{array}$ & $\begin{array}{c}\text { Type of } \\
\text { the } \\
\text { Substrate } \\
\text { Used }\end{array}$ & $\begin{array}{c}\text { Resonant } \\
\text { frequency } \\
\quad(\mathrm{GHz})\end{array}$ & $\begin{array}{l}\text { Return } \\
\text { Loss } \\
\text { (dB) }\end{array}$ \\
\hline [18] & $86 \times 74$ & $\begin{array}{c}\text { Taconic } \\
\text { Tly } \\
(\varepsilon \mathrm{r}=2.2)\end{array}$ & 1.237 & -61 \\
\hline [19] & $\begin{array}{c}380 \times \\
775\end{array}$ & $\begin{array}{c}\text { Rogers } \\
\text { RT5880 } \\
(\varepsilon r=2.2)\end{array}$ & 1.27 & -34.62 \\
\hline $\begin{array}{l}\text { This } \\
\text { work }\end{array}$ & $70 \times 70$ & $\begin{array}{c}\text { FR4 } \\
(\varepsilon \mathrm{r}=4.3)\end{array}$ & 1.265 & -69.78 \\
\hline
\end{tabular}

\section{Conclusions}

For GPS applications, new antenna design has been proposed with a square patch shape operating at L2 band (1.265) GHz. The characteristics of the antenna have been studied and the results are measured by using CST microwave studio version 19 . It was found that the antenna has a return loss $\mathrm{S} 11=-69.782 \mathrm{~dB}$, $\mathrm{VSWR}=1.0006$, gain $=4.9952 \mathrm{dBi}$ and real input impedance $=49.968 \Omega$ as well as the imaginary input impedance $=-9.2508 \mathrm{e}-05 \Omega$. Noting that all of the above results operating at the frequency 1.265 GHz. From that, one can conclude that the antenna has very good characteristics and can be modified to work at anther frequency and tested in a practical prototype as future work. 


\section{Acknowledgment}

The authors thank Al-Mustansiriyah university for their support of the scientific research activities.

\section{Conflict of Interest}

This research deals with the field of telecommunications, therefore, the party benefiting from it is mainly the Ministry of Communications.

\section{References}

1. A. El-Rabbany, Introduction to GPS: the global positioning system: Artech house, 2002.

2. G. Xu and Y. Xu, GPS: theory, algorithms and applications: Springer, 2016.

3. B. P. Narendra, "Micro strip patch antenna design for GPS application using ADS software," Journal of Information, Knowledge and Research in Electronics and Communication Engineering, vol. 2, pp. 475478, 2013.

4. Z. Hong-mei, N. Yan-juan, and L. Teng, "A novel GPS antenna with wide beam width," in 2010 2nd International Conference on Future Computer and Communication, 2010, pp. V1-49-V1-52.

5. N. JVSS, V. K. Kumar, B. Ramesh, and. K. P. Vinay, "Design of Microstrip Patch Antenna for GPS Applications using EBG Structures", International Journal of Innovative Research in Computer and Communication Engineering, Vol. 3, no. 3, pp. 2209 -2214, March 2015.

6. D. M. J. P. o. t. I. Pozar, "Microstrip antennas," vol. 80, no. 1, pp. 79-91, 1992.

7. C. A. Balanis, "Antenna theory: analysis and design". John Wiley \& sons, 2016.

8. Y. Lo, D. Solomon, W. J. I. t. o. A. Richards, and Propagation, "Theory and experiment on microstrip antennas," vol. 27, no. 2, pp. 137145, 1979.

9. S. K. Patel and Y. Kosta, "E-shape microstrip patch antenna design for GPS application," in 2011 Nirma University International
Conference on Engineering, 2011, pp. 1-4: IEEE.

10. M. L. Vishalkumar, K. Sandip, and S. S. J. E. J. o. A. E. Kashyap, "Design of planar microstrip patch antenna for GPS application," vol. 2, no. 3, pp. 32-36, 2015.

11. M. F. Bukhori, N. Misran, M. T. Islam, M. M. Yunus, and M. N. Shakib, "Design of microstrip antenna for GPS application," in 2008 IEEE International RF and Microwave Conference, 2008, pp. 464-466: IEEE.

12. N. K. S. Wah, and H. M. Tun, "Development of Microstrip Patch Antenna Design for $S$ Band Application", American Journal of Electromagnetics and Applications, Vol. 6, no. 1, pp. 17-23, 2018.

13. R. Garg, P. Bhartia, I. J. Bahl, and A. Ittipiboon, Microstrip antenna design handbook. Artech House, 2001.

14. A. J. I. J. o. S. Mehta and T. Research, "Microstrip antenna," vol. 4, no. 3, pp. 5457, 2015.

15. K. Carver, J. J. I. t. o. a. Mink, and propagation, "Microstrip antenna technology," vol. 29, no. 1, pp. 2-24, 1981.

16. Sh. Abdulkadhum, "Design and Implementation of Wideband Fractal Microstrip Antenna", M.Sc. Thesis, Middle Technical University, College of Technical Electrical Engineering, Sep 2018.

17. S. Nadhem, "Design and Analysis of Slotted Antenna for Wideband Applications", M.Sc. Thesis, AL-Mustansiriyah University, Dep. of Elec. Eng., Jan 2016.

18. S. K. Patel and Y. Kosta, "E-shape microstrip patch antenna design for GPS application," in 2011 Nirma University International Conference on Engineering, 2011, pp. 1-4: IEEE.

19. T. Khalifa, N. M. Sahar, N. Ramli, M. T. J. I. J. o. E. E. Islam, and C. Science, "Circularly polarized microstrip patch antenna array for GPS application," vol. 15, no. 2, pp. 920-926, 2019. 